«Автоматика-2008», 23-26 сентября 2008 г., Одесса, Украина. В 3-х томах. Т.1.Одесса: ОНМА, 2008. - С.9699.

26. Ларичев О.И. Наука и искусство принятия решений. - М.: Наука, 1979. -200 с.

27. Асланов С.К., Волков В.Э. Неустойчивость и структура детонации в схематизированной камере сгорания // Химическая физика, 2005. - Т. 24, № 7. - С. 86-90.

28. Асланов С.К., Волков В.Э. Неустойчивость и инициирование детонации // Тез. докл. ХІІ-го Симпозиума по горению и взрыву. - Черноголовка, Российская академия наук. - 2005. - С.129.

29. Дрёмин А.Н., Савров С.Д., Трофимов В.С., Шведов К.К. Детонационные волны в конденсированных средах. - М.: Наука, 1970.

30. Взрывные явления. Оценка и последствия: В 2-х кн. Кн.І / Бейкер У., Кокс П., Уэстайн ПІ. и др. - М: Мир, 1986. $-319 \mathrm{c}$

31. Зверев И.Н., Смирнов Н.Н. Газодинамика горения. - М.: Изд-во МГУ. - 1987.-307с.

\title{
ОСОБЕННОСТИ УПРАВЛЕНИЯ ТЕХНИЧЕСКИМИ ОБЪЕКТАМИ НА ТРАЕКТОРИИ РАСХОДОВАНИЯ РАСЧЕТНОГО РЕСУРСА
}

\author{
Воинова С. А., к.Т.н., доцешт \\ Одеская национальня академия пишевых технологий, г. Одесса
}

Нзложень особениости упрабления техническими объектами на траектории расходокания расчетного pecypa.

The features of control of technical objects on a pathway of spending of a design resource are stated.

Клочевье слова: угравление, технический объект, траектория, расходование, ресурс.

Технологические свойства технического объекта (ТО) на его траектори1и расходования ресурса (ТРР) непрерывно изменяются от свойств нового объекта до свойств объекта, изношенного, перешедшего в предельное состояние. Этим изменениям подвержены также регулировочные свойства (РС) ТО - параметры н характеристики - как объектов управления.

Технологичсскуло эффективность ТО формиругот ее составлягшие - экологическая, экономичсская и обшетехническая эффективность. Экологическая эффективность (ЭлЭ) является главным показателсм (критерием) степени совершенства ТО [1-3]. Далее будем использовать ее в качестве объекта анализа.

В экологических свойствах ТО заложены экологические возможности используемой технологии и возможности выполненной конструкция. САУ позволяет реализовать указанныс свойства ТО в его фактическую ЭдЭ

Новый ТО оснацают системой автоматического управления (САУ), регулятор которой настраивают на алгоритм, адекватный РС нового объекта и предназначенный для поддержания исходной ЭлЭ - ЭлЭ и (рис. 2). В гипотетическом случае, когда ТО не изнашивается, его ЭлЭ не изменяется во времени, остается на уровне ЭлЭ как угодно долго: график «а - b» (рис. 2). Применительно к подобному ТО понятие «ресурс» уграчивает смысл. Если рассуждать формально, то условный ресурс подобного ТО бесконечно велик. У реального же ТО с течением времени, вследствие износа, его РС изменяются. Это обусловливает непрерывнос снижение его ЭлЭ до уровня потенциальной - ЭлЭ - график «а - с» (рис. 2).

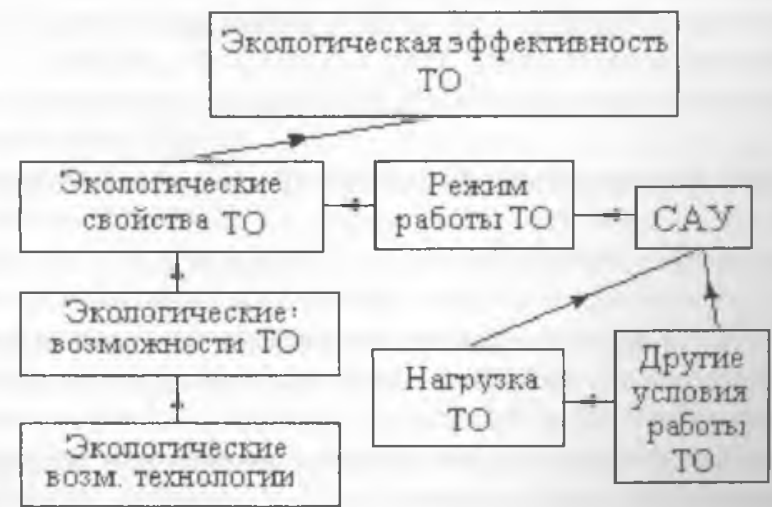

Рис. 1 - Структурно-логическая схема взаимодействия факторов, влияющих иа экологическую эффективность ТО 


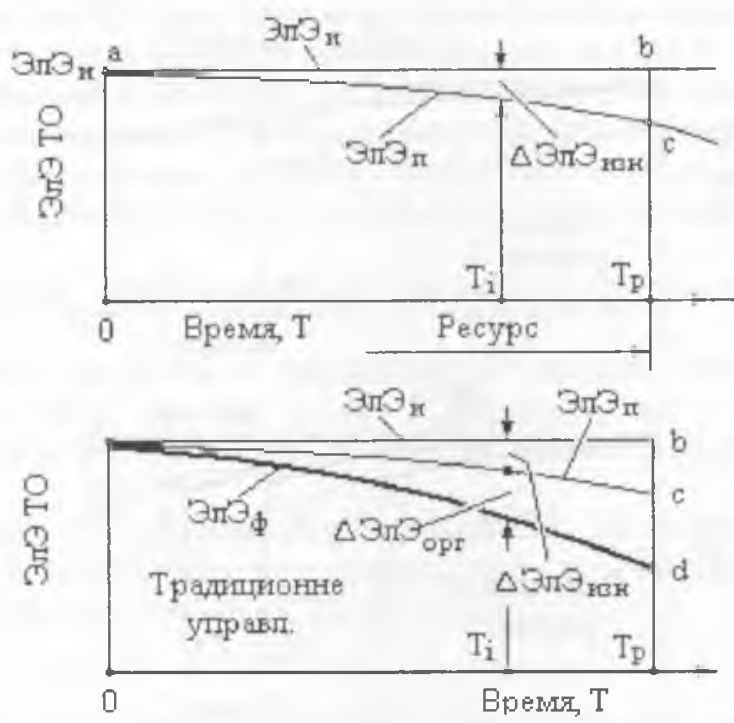

Рис. 2 - Изменение ЭлЭ ТО на траектории расходования ресурса

При снижении текушего уровня ЭлЭ п до минимально допустимого уровня (ЭлЭ мин), в момент времени Тр фиксируго завершение периода расходования ресурса и переход ТО в предельное состояние. Таким образом, с течением врсмсни (расходованием ресурса), по мере движсния ТО по ТРР его ЭлЭ неизбежно снижается (все более огдаляется от ЭлЭ

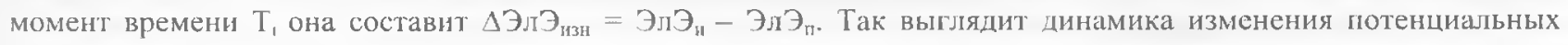
экологических свойств работающего ТО.

Далее, коснемся возможных способов управлениго режимом использования ЭлЭ ТО.

Способ 1. При традиционном способе алгоритм САУ разработан применительно к РС нового ТО. Поскольку ири пуске ТО в работу алгоритм адекватен его РС, САУ в состоянии в первый момент времени (Т, обеспечить управленне, при котором будет соблюдаться условие: ЭлЭ $=$ ЭлЭн. Однако, далее РС объекта измсняются (вследствие его износа), а разработанный алгоритм управления остается прежним. Теперь он оказывается неадекватным изменившимся РС. Поэтому САУ уже не в состоянии выполнять условне: ЭлЭ ЭлЭ

Вследствие этого, обеспечиваемые САУ фактические показатели работы ТО, в частности его ЭлЭђ, снижаются (график а - d, рис. 2), т.е. отдаляются от соответственных по времени потенциальных значений (ЭлЭ ). Важно отметить то, что возникший спад показателей состонт из двух частей:

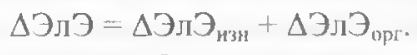

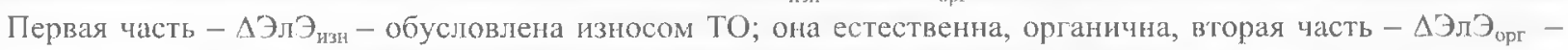
обусловлена накопившинся со временем несоответствнем (сложившимся противоречием) между нзменившимися РС ТО и оставшимся нензменным алгорнтмом управления им. То есть, вторая часть вызвана недостатком в организации взаимодействия элементов системы «объект управления - САУ». $Э$ ЭЛ характеру функциональна.

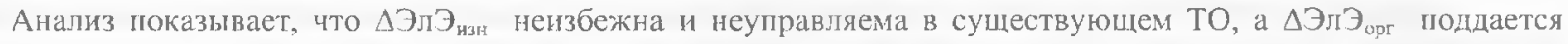
управлению путем коррекции алгоритма управления.

Способ 2. Если коррекцию алторитма осупествлять непрерывно на всей ТРР, то почва для появления

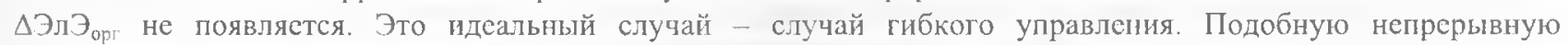
коррекцию алгоритма способна осушествлять САУ, адаптивная по отношенлю к непрерывно изменяющимся РС объекта.

В этом случае функция ЭлЭ

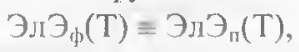

то есть график ЭлЭ

Способ 3. Если коррекцию алгоритма осуществлять периодически, через выбранные перноды времсни, то почва дия появления $\triangle Э_{\text {орг }}$ останется, однако ее влияние можно существенно сократить и на этой основе реализовать случай полугибкого управления. В этом случае, в конце начального участка ТРР, например, в момент времени $T_{l}$, (рис. 3), проводят первый шаг коррскции алгоритма: устраняют накопившуюся неадекватность алгорнтма уровню ЭлЭп; этим ЭлЭ повышают до уровня ЭлЭ точку «е» поднимают до уровня «ф».

Далее, в период времени $\left(\mathrm{T}_{2}-\mathrm{T}_{1}\right)$ ТРР изображена дугой «f - h», эквидистангой дуге «е - п» - части ТРР ЭлЭ момент проводят второй паг коррекции алгоритма, чем переводят рабочую точку ТРР из положения «һ» в положение «g». В момент времени $\mathrm{T}_{3}$ проводят третий шаг коррекции алгоритма. 


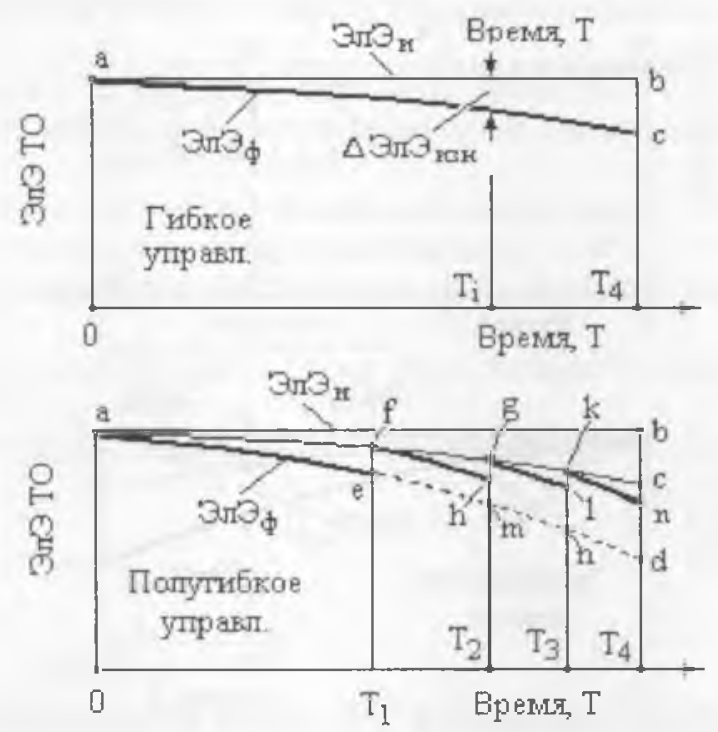

\section{Рис. 3 - Изменение ЭлЭ ТО на траектории расходования ресурса при гибком и при полугибком} управлении

Анализ показывает то, что в результате выполнения трех коррекций алгоритма ТО прослсдовал по ТРP ЭлЭ, изображенной на рис. 3 кривой «aethglkn». Если бы коррекции не проводили бы, то траекторию изображала бы кривая «aehmndc», отвечающая случаю использования традиционного способа, при котором шсходный алгоритм не корректируют.

Изложенное показывает, что

- применение полугибкого управления позволило на ТРР после первого шага коррекции обеспсчить существенио более высокий уровень ЭлЭ, чсм при традиционном способе. В конце последнего периода абсолютное улучшение (повышение) ЭлЭ

○ по эффективности нспользования возможностей Эл'Э ТО полугибкое управление уступает гибкому управлению,

○ полугибкое управление сушественно превосходит традиционное управление,

- при заданном уровне минимально допустимой ЭлЭ (ЭлЭ управления к гибкому способу обусловливает сушественное увеличение ресурса ТО (рис. 4),

- увеличением числа вводимых коррекций алгоритма эффективность полугибкого способа управления приближается к эффективности гибкого способа. Исходя из этого, можно считать, что при бесконечно бољьшом числе коррекций (то есть при непрсрывно вводимой коррекции) полугибкий способ становится ндентичным гибкому,

- практическое примененис гибкого способа управления усложнено тсм, что необходимо располагать закономериостью изменения ЭлЭ ТО во времени из-за износа (то есть необходимо знать функцию ЭлЭ $(T)$ ),

- эффективность грименение полугибкого управления прогрессивно возрастает по мере движения ТО по TPP,

- переводить ТО с традиционного способа управления на способ полугнбкого управления тем целесообразнее, чем меньше их остаточный ресурс.

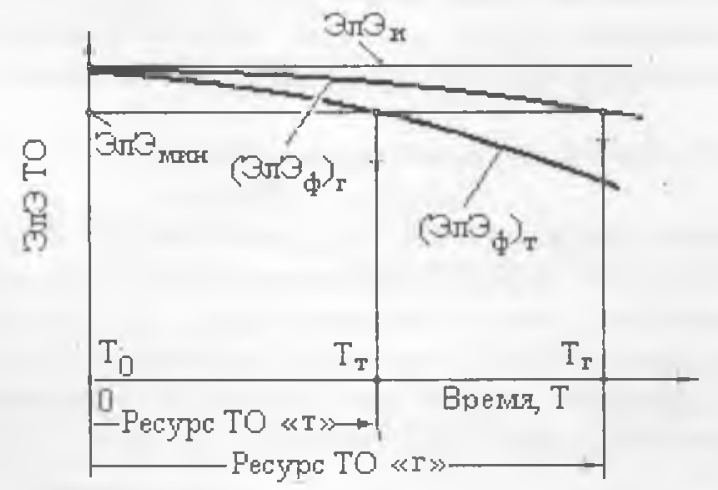

Рис. 4 - Влияние способа ушравления ТО на его ресурс

\section{Выводы}

1. Параметры и характеристики ТО (как объектов управления) при их движения по траектории расходования ресурса подвержены изменению под действием износа этих объектов. 
2. По мере движения ТО по ТРР под действием износа его исходная ЭлЭ непрерывно снижается и представляет в каждый момент времени переменную - потенциальную - ЭлЭ.

3. То, какую часть реализуемая фактическая ЭлЭ ТО составляет от потенциалььнй, зависит от способа управления этим объектом. Особенности способа ущравления ТО сущесгвенно влияют на их фактическую ЭлЭ.

4. Наяболее высокой эффективностью обладает гибкий способ управления. Однако ему свойственна некоторая сложность. Он перспективен особенно для производства, нуждаюпегося в особо высоком качестве управления.

5. Относительно невысокой эффективностью характеризуется наиболее простой в реализации традиционный способ.

6. Эффективность способа полугибкого управления с помощью периодического корректирования алгоритма регулятора может быть сделана близкой эффективности способа гибкого. Этот способ характеризуется повышенной перспективностью в сфере производства с высокими требованиями к качеству управления.

7. Применение полугибкого и, особенно, гибкого управления, ло сравнению о традиционным, требуют увеличенного вложения ресуров. Однако, их превосходит положительный эффект, обусловленный значительным повышением качества управления и увеличением ресурса ТO.

\title{
Литература
}

1. Воінова С.О. Можливості управління екологічнољо характеристикою технічних об'єктів. // Тр. 11-ой Междунар. н.-т. конф. «Физич. и компьютерн. технологии» (02-03 июня 2005 г., Харьков). - Харьков: ХНПК «ФЭД》. $-2005 .-$ С. 221-223.

2. Воннова С.А. Актуальные задачи управления экологической эффективностью технических объектов. // Матер. Междунар. конф. «Стратегия качества в промышленности и образовании». (1-8 июня 2007 г., г. Варна, Болгария). - Днепропетровск - Варна: «Фортуна». - ТУ Варна. - 2007. - Т. 1. - С.102-104.

3. Воннова С.А., Сычук Л.М. Пути непосредственного управления экологической эффективностыю котельнотопочных систем. // Наукові праці ОНАХТ. - Мін. освіти і науки Украйни. - Одеса, 2007. - Вип.. 31. - Т.1. C. 159-161.

УДК: $621.57-53$

\section{АНАЛИЗ ВЛИЯНИЯ ПРОБНЫХ ДВИЖЕНИЙ ВБЛИЗИ ТОЧКИ ЭКСТРЕМУМА НА ПЕРЕХОДНЫЕ ПРОЦЕССЫ В ХОЛОДИЛЬНОЙ УСТАНОВКЕ}

\author{
Гурский А.А., аспирант \\ Одесская государственная академия холода, г. Одесса
}

B статье отражены идеи реапизаиии системы поиска экстремуяа при многоуровневой координиружией системе управления. Предспавлены результапы математических эксперинентов, направленных установить влияния пробных движений вбпзи точки экстремума на переходные процессы в холодильной установке.

It is considered realizations of search of an extremum at a coordinating control system. Results of mathematical experiments of the trial movements connected with influence near to a point of an extremum are presented.

Ключевые слова: координирующая система управления, компрессор, экстремум, расчетный блок.

\section{Введение}

Применение комбинированного регулирования производительности центробежного турбокомпрессора (ЦБК) холодильной установки по двум управляющим воздействиям, по углу установки лопаток диффузора $\alpha_{д}$ и по скорости вращения вала $n_{v}$, позволяет получить нанбольшее значение $\eta$ КПД турбокомпрессора и наименьшую потребляемую мощность $N_{L L K}$ [1]. Беспонсковая система, реализующая комбинированное регулированис производительности ЦБК с целью получения наибольшего значение $\eta$ КПД, имеет преимущество по сравнению с поисковой системой, связанное с отсутствие поиска и недостаток - возможность выхода в точку недостоверного экстремума КПД ЦБК.

В настоящей работе отражается идея реализацин поисковой системы ири многоуровневых (координирующих) систем управления холодильной турбокомпрессорной установкой (ХТУ) [2,3]. Проводиться ряд математических экспериментов для определения влияния пробных движений вблизи точки экстремума на переходные процессын.

Основная часть

Разработанные разлючные модели многоуровневых систем уиравления, а именно координирующая система $(\mathrm{KCУ})$ и система управления с расчетным блоком (РБ), реализуют комбинированное регулирование 